\title{
THE SOCIAL MEDIA IMPACT ON YOUNG PEOPLE'S PERCEPTION OF THEIR BODIES AND THEMSELVES.
}

\author{
Ovchinikova D.A. \\ S. Amanzholov East Kazakhstan University, e-mail: diana.ovchinikova00@gmail.com \\ Recently social media was associated with low self- esteem and body concerns among the younger genera- \\ tion. Therefore, this has led to an interest in exploring young people's use of social media to understand the impact. \\ This study examined the relationships between social media use and young people's body dissatisfaction and eat- \\ ing diseases. Another aim was to review the benefits of body positivity, body neutrality and social media literacy. \\ Since young people most affected by SM due to immaturity and a great deal of time spent on social networking \\ sites. Young students of both sexes participated in the interview. Although they had body concerns, most of the \\ participants showed a high level of social media literacy. Furthermore, the ideas on dealing with the negative impact \\ of social media on body perception. The investigation provides the impact of SM on young people's perception of \\ their bodies, benefits of body positive content on SM, and some of the potential solutions from detrimental effects \\ of social media.
}

Keywords: social media, body image, eating behaviors, body positivity, social media literacy, young people

\section{Context}

The beginning of the $21^{\text {st }}$ century was the moment when social networking sites appeared and started to spread all around the world, consequently, nowadays these sites became a principal part of people's lives [1]. Social media give people the opportunity to communicate, share information, ideas, photos and other various content [2]. Social networking sites appear as the field for global cyber- communication, education, or space for leisure activities and entertainment. Hereby social media should be understood as a new cultural tool [3]. Nowadays, according to Clement, there are 9 major social networks with more than 100 million active users, for instance, Facebook has about 1 billion users [4]. The number of people using SM (social media) is rapidly increasing. According to the newest report by Clement, internet users worldwide spend 144 minutes per day on SM [5]. As reported by Anderson \& Jiang, most teens have smartphones and access to the internet [6]. They also indicated that $45 \%$ of youngsters "are online on a near-constant basis" [6, p. 2]. SM has also been associated with body image perception and has often been criticized due to presenting appearance standards that can lead to an unhealthy perception of a body by young people [7]. Physical appearance indicates how one looks. People tend to judge one's character and personality from an individual's outward appearance, therefore the way people look has always been perceived by society as an integral and important part of life.

\section{Research problem}

Since SN (social networks) started to play a significant part in young people's daily routine, it has begun to affect their life. Numerous researches have concluded that SM usage might be problematic due to its causing low well- being, mental problems, depressive symptoms [8]. Body dissatisfaction is the neg- ative thought a person has about his $\backslash$ her body. Body dissatisfaction refers to several negative consequences such as lowered self- esteem, depression, social anxiety, unhealthy dieting, and eating disorders [9]. Adolescence is the period of life when a person mostly focused on appearance [9]. SM is the field where people share the content, usually, images or photos, from celebrities, friends and random people such content is viewed by young people for inspiration about the way beauty or body should look [10]. However, few studies have investigated whether SM helps young people to appreciate and love their body the way it is or it does not affect the perception of adolescents' body images [11]. A body positivity movement has appeared on SM and immediately became a challenging aspect of regular idealized images posted online [12]. However, there is some criticism on such a topic [13].

\section{Research purpose}

Since the usage of SM appears to be influential on the lives of youngsters, many researchers attempted to study the relationship between problematic SM usage to body perception, eating behaviours and self- esteem. However, the investigations were conducted on a restricted basis by picturing only detrimental $\backslash$ beneficial causes or focusing on just one gender, usually female. Therefore, the current study aims to include a more gender-balanced exploration. Furthermore, there are limited studies focused on the effects of body-positive SM content on aspects of body perception. The study also suggests options for preventing the possible negative effects of social networks.

\section{Research questions}

1. The role of social media in the lives of young people.

2 . The impact of social media on young people's perception of themselves and their bodies?

3 . How to be safe on social media? 


\section{Research significance}

According to the possibility of negative effects of SM use, there is a need for SM literacy in the field of education and family. This study was done to prevent the possible negative effects of SNS (social networking sites). Thanks to this study, educational institutions and families will be more interested in the mental state of young people and their perceptions of themselves. Adults who have a responsibility for young people's health and wellbeing must be supported to become sufficiently digitally literate so they, in turn, are able to support young people to use social media safely and in ways that generate positive mental health outcomes. Young people should be educated in the field of SM.

\section{Literature review}

\section{Methodology}

The sources for the current literature review were selected according to the research's publication date, citation frequency, relevance, and availability in a full text throughout the database- Google Scholar. The timeline for the chosen literature spanned from 2007 to 2020 . Using the advanced search feature of the database, the following keywords were used: social media, body image, body perception, body dissatisfaction, young people, mental health, self- esteem, eating disorders, body positivity, body neutrality. Other background information and definitions were obtained through various online resources.

\section{Review of Previous Researches}

Recently many researchers studied social media as the object of influence on appearance's comprehension by young people. In this literature review the main themes appeared during the analysis of the studies, they are body dissatisfaction, body positivity, and body neutrality. These three terms were chosen to examine and expose the processes within SN that led to detrimental and beneficial outcomes of social media usage in relation to body image and SM literacy.

\section{Body dissatisfaction}

Several studies suggested the link between body dissatisfaction and SM usage due to a number of reasons. One of the indicators causing harmful body concerns is social comparison theory, which indicates the process of people's self- evaluating by comparing with others. Jan et al. reports that such comparison on social networking sites is divided into upward and downward [1]. While the first one refers to comparing oneself to superior someone, the latter one indicates comparisons with worse ones, therefore upward comparison makes people feel inferior and has negative evaluations of themselves. This chapter will describe upward comparison, which includes body concerns, low self- esteem, eating disorders, and body dissatisfaction.

Jong \& Drummond examined the use of SM by adolescents with an intense focus upon appearance [10]. They conducted focus- group interviews that supported the hypothesis of the influence of SM on body concerns and unhealthy eating practices [10]. It was also clear that the participants were inspired by beauty and body shape from the images posted on SNS. Another research suggests a connection between eating disordered behaviours, increase body dissatisfaction, and adverse effects of exposure with unrealistic, idealized content posted online [14].

Young people tend to compare their own bodies with the "ideal" portrait of the body shown on SM, therefore such attitudes result in low self- esteem [15]. The problem of body perception engages not only females but also males since they are also affected by the muscular and fit bodies shown online [15]. The research of Jan et al. clearly shows that Facebook affects negatively the self- esteem of individuals, since people visit and envy other's profiles considering them to be more superior [1]. Therefore, SM users feel inferior and ungrateful.

\section{Body positivity and body neutrality}

Recently some researchers explored the appearance and process of body positivity movement. Since SM started to present "ideal" bodies, the opposite movement became widespread on many platforms on the Internet, with over 11 million posts tagged with 60 \#bodypositive, 4 million for \#bodypositivity [13].

The goal of the movement is to challenge idealized physical appearance and respect all body types, while mainly focusing on health [12]. Images of bodies with normal weight and obesity on SM promote body acceptance [13].

Some researchers report on the beneficial causes of positive body images on SM, such as love for the body and emotional well- being. However, there is a critic of the movement due to its pressure to love one's body and the underlying issue of keeping the focus on the body [13].

As the body positivity movement became prevalent on SM, the idea of body neutrality was also added. The concept behind body neutrality proposes to put less accent on the appearance altogether, however, it seems dif- 
ficult for today's society with an everyday reminder that an individual should have a perfect body [13].

\section{Social media literacy}

Although social media leads to body concerns among young people, studies are reporting that partly young people are capable to think critically and objectively about what they face on SM [11]. The participants of the study informed that such behaviours were received by parents and schools.

\section{Methodology chapter}

\section{Introduction}

Initially, I wanted to name this research as "Life in the era of Social Media from the young people's perception: the impact on life, self-confidence, and reception of body" "but then I realized that this name would generalize the field of the study. Therefore, I've decided to clarify the topic of the study by calling it "The impact of social media on young people's perception of their bodies and themselves". Consequently, the purpose of the study was to understand how such a phenomenon as social media affects the lives of young people in terms of appearance.

The next chapters provide an outline of the research methodology used to answer the research questions- the research approach, a description of the data collection process for the interviews, data analysis, and techniques used.

\section{Research design justification}

For the purposes of this project, I've elected literature suggested to the theme of the study. Searches on Google Scholar revealed that generally, social media perceived as the environment that affects body perception negatively. However, on the flip side of the coin, there also were studies focusing on beneficial attributes of SM usage. To support the research the interviews were conducted.

\section{Data collection}

According to the name and goal of the research, the participants were chosen among young people. This investigation involved six people aged 19 to 24 . Four of the participants were women and two were men. It was not complicated to find the participants, since I knew all of them. Some of the participants that I interviewed were invited from Amanzholov University and some were from the author's surroundings. The interviews were conducted face to face and recorded on tape. In average interviews lasted for 25- 30 minutes. When the data was collected, I started to analyze the information. In addition, the current findings should be understood in the light of possible limitations, since this was small research conducted for academic purposes and it was limited to the students of Amanzholov University. The sample was also kept short due to time constraints. It is also important to mention whether the sample is a true representation of all people or not. Although the interview was well-structured honesty of the participants cannot be measured, since many factors can lead to unreliable replies by the students.

\section{Data analysis}

First of all, after collecting the data I transcribed the interviews. Transcribing consisted of converting the whole dialogue between the respondent and interviewer into the typed text. The next step was to code the interviews, which I did from line to line drawing out words, phrases, and sentences that assign summative attributes for a portion of data. Afterwards, I identified patterns among codes and came up with themes. This thematic analysis is based on the work of Braun and Clarke.

\section{Ethics}

Ethical issues were taken seriously, so we explained to our participants that the data collected would not bridge any confidentiality, therefore the names of the participants were disguised. The author stored the data carefully, so no one had access to it.

\section{Findings and conclusions}

1. The role of social media in the life of young people.

Generally, young people spent 4 to 8 hours on SM. Mostly young people spend time on social networks during night time, since they have more extra time. The most popular and prevalent SNS are Instagram, WhatsApp, and VK. SNS have many benefits and offer diverse opportunities. Young people use such sites to chat with friends and share content and ideas.

Social networks provide an opportunity to show others what you are doing at the moment, set your photos, show your activities. (Anna, female 21)

Furthermore, using SM dives the opportunity to find out the latest news and get any required information. Some use social networks for online shopping since they find it very convenient.

Instagram gives information that you can see, or you can now read all the news on Instagram. Especially about coronavirus. (Irina, female 24)

I pay more attention to online shops. Especially for clothes. Because I don't have much time now, I open Instagram and search for what clothes they have available. And I save them and when the time comes I look at which I chose. (Irina, female 24) 
2. Impact of social media on young people's perception of themselves and their bodies.

$\mathrm{SN}$ is a huge platform for sharing and disseminating any information, whether it's photos, music, or messages. Pictures of wealth, success, and beauty are the most spread and common on SM, many of the accounts showing this lifestyle are not completely honest with their audience. Some use Photoshop, pick a camera lens and special locations for their photos. Others also create an aura of "perfection" in their lives, which later opens up. Thus, young people often fall under the influence of such an "ideal picture" and begin to look for defects in themselves, thereby harming their self-esteem.

Always layout that they are travelling. They begin to brag about it, thus, I do not know, offend some low-income people. (Mark, male 20)

Photos of an insanely beautiful place or they went on a trip and from there they upload photos, that is, not everyday ones, namely thoughtful photos, the angle, clothes, and so on are selected. (Esmeralda, female 19)

Interviewer: How do you rate your appearance after viewing such accounts?

Mark: I think about myself that I am of such an average build (frowns), not very pretty on my face. (Mark, male 20)

In addition to all of the above, the propaganda of an unhealthy lifestyle, including anorexia, is spread on social networks. Such communities, romanticizing anorexia prevail on Vkontakte, as well as occur on Instagram. Participants in these communities are young people, mostly teenage girls.

It seems to me that social networks influence, they can promote such an appearance (anorexia) and, for example, young people can rely on it because they will count once it is displayed, it means it's beautiful, they want to be that way. (Anna, female 21)

On the flip side of the coin, social networks assist young people who have lost themselves or are insecure about themselves. Many accounts teach young people how to love themselves and provide all kinds of support, while others set an example of how to achieve their goals.

For example, I used to follow one girl at one time, and now she has become a host of travel programs, travels around the world, and when I look at her, I think, "Wow, you have achieved a lot, I'm proud of you." And, it seems to me, people, therefore, look to understand and see that if you want, you can achieve anything. There are also motivating ones, again a lot about travelling, and there are body-positivists, there are feminists. Body positivists talk about how important it is to love your body and this, I think, helps people who can't accept themselves and this kind of content helps people overcome their problems. (Esmeralda, female 19)

Overall most of the participants showed that social media does not negatively influence their perception of their physical appearance. They showed confidence and healthy self- esteem.

No, I think it doesn't matter anymore, because I accept myself and my appearance. I realized that there is me, and there are other people, and even if they do something better than me, or they look better than me, but they are the same living people, they have the same problems, they have their own life, I have my own, there are moments in which I am better, there are moments in which I am worse and this is normal. (Esmeralda, female 19)

People who run this account post only a limited part of their lives, create the perfect picture and the person who looks at it thinks "Damn, she's so amazing, she's doing so well, she has a great appearance, a loving husband, or a lot of money, but I don't have all this. " But they do not see the problems that this person has and idealize him and because of this, self-esteem is very much destroyed. (Anna, female 21)

Interviewer: Do you think these accounts somehow affect your self-confidence?

No, not at all. (Islam, 21)

3. How to be safe on social media.

Most young people fall under the influence of social networks, so this affects their self-esteem and can even harm it. This is often since young people have immature self-esteem and often compare themselves with peers and older people. Thus, schools and adults play an important role in keeping youngsters safe on the Internet. There should be curriculums aimed at developing SM literacy, therefore children and young people will be able to critically perceive the content posted online. However, it is important to negotiate young ones in the field of $\mathrm{SM}$, instead of prohibiting and imposing rules since it can lead to conflicts and even worsen the situation. Society should pay attention to the existence of such a problem, since low selfesteem, self-doubt can lead to big problems and interfere with a normal life.

It is necessary to help children, adolescents to develop self-confidence. That is, parents must do this, peers must do it, psychologists must do it. And social networks are just a resource that they use. (Esmeralda, female 19) 


\section{Summary of all themes, concluding thoughts.}

Overall the investigation showed that while participants know the possibility of SM negative affection they still were able to critically embrace the content of social media. However, in light of the limitations of the study, there is still a need for further exploration. In conclusion, future investigations should include the differences between various ethnic groups, occupations, and social status. According to these factors, researchers may determine the connection between SM and body dissatisfaction and eating disorders.

In the end, the author wants to mention that while SM is just a virtual reality, people within it are real. Therefore, the problems we have in the real world were simply transferred into digital ones. Consequently, the problems of SM are the issues of society that remain to be solved.

\section{References}

1. Jan M., Soomro S., Ahmad N. (2017). Impact of social media on self-esteem. European Scientific Journal, 13(23), 329-341.

2. Merriam-Webster. (n.d.). Social media. In MerriamWebster.com dictionary. September 21, 2020; URL: https:// www.merriam-webster.com/dictionary/social \%20media

3. Greenfield P.M., Subrahmanyam K. (2003). Online discourse in a teen chatroom: New codes and new modes of coherence in a visual medium. Journal of Applied Developmental Psychology, 24(6), 713-738.

4. Clement J. (2020, August 21). Most used social media platform. Retrieved September 24, 2020, from https:// www.statista.com/statistics/272014/global-social-networksranked-by-number-of-users/
5. Clement J. (2020, February 26b). Daily social media usage worldwide. Retrieved September 24, 2020, from https://www. statista.com/statistics/433871/daily-social-media-usage-worldwide/

6. Anderson M., Jiang J. (2018). Teens, social media \& technology 2018. Pew Research Center, 31, 2018, p. 2-5.

7. Hargreaves D., Tiggemann, M. (2003). The effect of "thin ideal" television commercials on body dissatisfaction and schema activation during early adolescence. Journal of youth and adolescence, 32(5), 367-373.

8. Marino C., Gini G., Vieno A., Spada M.M. (2018). The associations between problematic Facebook use, psychological distress and well-being among adolescents and young adults: A systematic review and meta-analysis. Journal of Affective Disorders, 226, 274-281.

9. Hargreaves D., Tiggemann M. (2002). The effect of television commercials on mood and body dissatisfaction: The role of appearance-schema activation. Journal of Social and Clinical Psychology, 21(3), 287-308.

10. Jong S.T., Drummond M.J. Shaping adolescent girls' body image perceptions: the effect of social media on Australian adolescent girls // Research and Scientific Committee. - 2013. T. 74, p. 74-80.

11. Burnette C.B., Kwitowski M.A., Mazzeo S.E. (2017). "I don't need people to tell me I'm pretty on social media:" A qualitative study of social media and body image in early adolescent girls. Body Image, 23, 114-125.

12. Sastre A. (2014). Towards a radical body positive: Reading the online "body positive movement". Feminist Media Studies, 14(6), 929-943.

13. Cohen R., Fardouly J., Newton-John T., Slater A. (2019). \# BoPo on Instagram: An experimental investigation of the effects of viewing body positive content on young women's mood and body image. New Media \& Society, 21(7), 1546-1564.

14. Aparicio-Martinez P., Perea-Moreno A.J., MartinezJimenez M.P., Redel-Macías M.D., Pagliari C., Vaquero-Abellan M. (2019). Social media, thin-ideal, body dissatisfaction and disordered eating attitudes: An exploratory analysis. International journal of environmental research and public health, 16(21), 4177.

15. Glazzard J., Stones S. (2019). Social media and young people's mental health. In Technology and Child Mental Health. IntechOpen, p. 3-8. 